Research Paper

\title{
Pretreatment TG/HDL-C Ratio Is Superior to Triacylglycerol Level as an Independent Prognostic Factor for the Survival of Triple Negative Breast Cancer Patients
}

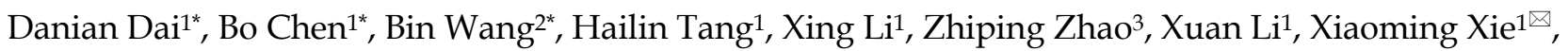 \\ Weidong Wei ${ }^{1 凶}$
}

1. Department of Breast Oncology, Sun Yat-Sen University Cancer Center, State Key Laboratory of Oncology in South China, Collaborative Innovation Center for Cancer Medicine, Guangzhou, China;

2. Institute of Life Science, Chongqing Medical University, Chongqing, China;

3. Institute of Hepatopancreatobiliary Surgery, Southwest Hospital, Third Military Medical University, Chongqing, China.

*These authors have contributed equally to this work.

$\triangle$ Corresponding authors: Weidong Wei, e-mail: weiwd@sysucc.org.cn, phone: 020-87343806 Or Xiaoming Xie, e-mail: xiexm@sysucc.org.cn, phone: 020-87342636 Department of Breast Oncology, Sun Yat-Sen University Cancer Center, 651 East Dongfeng Road, Guangzhou, 510060, People's Republic of China.

(C) Ivyspring International Publisher. Reproduction is permitted for personal, noncommercial use, provided that the article is in whole, unmodified, and properly cited. See http://ivyspring.com/terms for terms and conditions.

Received: 2016.04.07; Accepted: 2016.06.26; Published: 2016.08.07

\begin{abstract}
Purpose: Previous studies have reported that the triacylglycerol (TG) level and high-density lipoprotein cholesterol (HDL-C) are connected with breast cancer. However, the prognostic utility of the TG level and the TG/HDL-C ratio (THR) as conventional biomarkers in patients with triple negative breast cancer (TNBC) has not been elucidated. In this research, we investigate and compare the predictive value of the pretreatment serum TG level and THR in TNBC patients.

Methods: We evaluated 221 patients with TNBC who had pretreatment conventional blood biochemical examinations and calculated the THR. Univariate and multivariate logistic regression analyses were used to assess the effect of the TG level and the THR on overall survival (OS) and disease-free survival (DFS).

Results: The optimal cutoff values of the TG level and the THR were determined to be 0.935 $\mathrm{mmol} / \mathrm{L}$ and 0.600 , respectively. As shown in a Kaplan-Meier analysis, TNBC patients with a high TG level and THR had shorter OS and DFS than patients in the low-level groups $(p<0.05)$. The multivariate analysis suggested that the pretreatment THR level is an independent prognostic factor of OS (HR: 1.935; 95\%Cl: 1.032-3.629; $p=0.040$ ) in TNBC patients.

Conclusions: In conclusion, our data indicate that a high THR is an independent predictor and is superior to the TG level for predicting poor clinical outcomes in TNBC patients.
\end{abstract}

Key words: triple negative breast cancer; TG; THR; TNBC; prognostic factor.

\section{Introduction}

Breast cancer is a heterogeneous disease that consists of luminal A, luminal B, HER2+, and triple negative types. These disease subtypes are based on hormone receptor [estrogen (ER) and progesterone receptor (PR)] status and HER2 gene amplification [1]. In addition to surgery, oncologists employ the following three types of therapy: (1) Hormone receptor-positive patients can be treated with hormone receptor-targeted drugs (such as tamoxifen) \pm chemotherapy; (2) patients with HER2 gene amplification should receive HER2-targeted therapy (such as herceptin) \pm chemotherapy; and (3) patients with negative hormone receptors (ER and PR) and absence of HER2 should receive only chemotherapy 
treatment. Compared with tumors in other molecular subgroups [2-4], triple negative breast cancers (TNBC) more frequently occur in younger women $(<50$ years) [5-7] and have notably stronger metastatic capacity and a higher-grade pathology classification. Therefore, TNBC is considered the poorest prognosis type of all breast cancer subgroups. Owing to the varied clinical treatment responses and survival rates observed for molecular subtypes of breast cancer, research on breast cancer biomarkers and molecular classification has important significance for guiding clinical treatment and judging prognosis.

TNBC remains an intractable disease worldwide. Previous studies have reported that Wnt5a [8], NLR [9] and PELP1 [10] have significant prognostic value in TNBC. Patients with cancer usually experience dystrophy, which accounts for the survival rate of these cancer patients [11]. Serum lipids can effectively assess nutritional status [12], and lipid disequilibrium has been observed in cancer patients [13]. The potential value of conventional biochemical detection indexes has been extensively examined. For example, decreased levels of HDL may predict worse outcomes in TNBC patients [14]. Additionally, low-level plasma cholestrol, high-density lipoprotein cholesterol (HDL-C), and phospholipid levels are prognostic in patients with non-Hodgkin's lymphoma or prostate carcinoma [15].

Several studies $[14,16,17]$ have reported that serum lipids and serum triacylglycerol (TG) levels are associated with breast cancer. However, the associations between specific lipid metabolism biomarkers, such as low-density lipoprotein, and breast cancer are inconsistent [18,19]. In addition, a limited number of studies have evaluated the significance of the pretreatment TG/HDL-C ratio (THR) in triple negative breast cancer patients as a prognostic factor of survival. Therefore, the purpose of this research was to explore whether the THR is correlated with the outcome of TNBC patients and, if this correlation exists, how the THR compares with the TG level as a prognostic factor.

\section{Materials and methods}

\section{Patients and methods}

Each participant has signed the written informed-consent before using their venous blood samples. The study was approved by the ethics boards of Sun Yat-sen University Cancer Center. We retrospectively collected the clinicopathologic data of triple negative breast cancer patients who received modified radical mastectomy from January 2004 to December 2009 at Sun Yat-sen University Cancer Center. The inclusion criteria for the study included the following: all patients had confirmed TNBC by pathology, and no patients had received any treatments before collection of the blood samples for biochemical data. The exclusion criteria for the study included the following: (1) coexisting cancer; (2) lack of original blood biochemical tests acquired before treatment; (3) overweight (BMI>25) or abnormal lipid metabolism disease; (4) lack of follow-up data; and (5) lack of other necessary information.

\section{Clinical data collection}

The medical records were queried using an electronic medical record system, and each patient's medical history, age, BMI, menopause status, pathology parameters (such as tumor size, lymph node status, hormonal status, HER-2 status, and histological grade), and laboratory data were collected. The clinical stages of the disease were determined by the TNM staging system according to the AJCC (American Joint Committee on Cancer Classification, $7^{\text {th }}$ edition, http://www.cancerstaging. org). Triple negative breast cancer was defined by pathology as ER-, PR-, and HER2-.

\section{Biochemical determinations}

A blood analyzer (Hitachi Automatic Analyzer 7600-020 [Hitachi, Tokyo, Japan]) was routinely used to test the baseline serum triglyceride and HDL-C levels of pretreatment blood samples. The ratio of the parameters (THR) was retrospectively calculated. The cut-off values of the TG level and the THR determined by the receiver operating characteristic curves (ROC) were $0.935 \mathrm{mmol} / \mathrm{L}$ and 0.600 , respectively. The value was considered high or low relative to the cut-off value.

\section{Follow-up and study endpoints}

The patients were followed up by telephone interviews every 3 months for the first 3 years and then every 1 year to determine relapse or death. The first day of follow-up was defined as the date of the definite pathological diagnosis. The last follow-up date to confirm the final conditions of all available patients was 27 November 2015. One of the primary endpoints of the study was overall survival (OS), which was defined as the period of time from definite pathological diagnosis to death or the date of the last follow-up. Disease-free survival (DFS) was the other primary endpoint, which was defined as the period of time from definite pathological diagnosis to the local recurrence or distant metastasis, death, or new neoplasms.

\section{Statistical Analysis}

The optimal cutoff values for the TG level and the THR were calculated using receiver operating 
curve (ROC) analyses. The patient demographic distribution and the distribution characteristics of the TG level and the THR in various clinical variables were expressed as the mean \pm standard deviation on the means of the descriptive statistics. The correlation between patient characteristics and pretreatment serum biomarkers was evaluated by unpaired t-test or one-way analysis of variance (ANOVA). The differences between proportions were examined using the Chi-squared test. The survival analyses were calculated through the Kaplan-Meier method. The discrepancy between the groups was identified by a log-rank test. The independent variables associated with OS and DFS were identified by univariate and multivariate analyses. All of the significant parameters in the univariate analyses were examined in a multivariate model after excluding the insignificant explanatory variables $(P>0.05)$. A P-value less than 0.05 was considered statistically significant.

\section{Results}

\section{The medical records screening process and the histologic subtype}

The screening process is depicted in Fig. 1. This study examined 502 TNBC patients who were selected during an electronic medical record review. There were 279 patients eliminated from the study because can't satisfy the inclusion criteria. There were 25 patients with coexisting cancers, and 82 patients

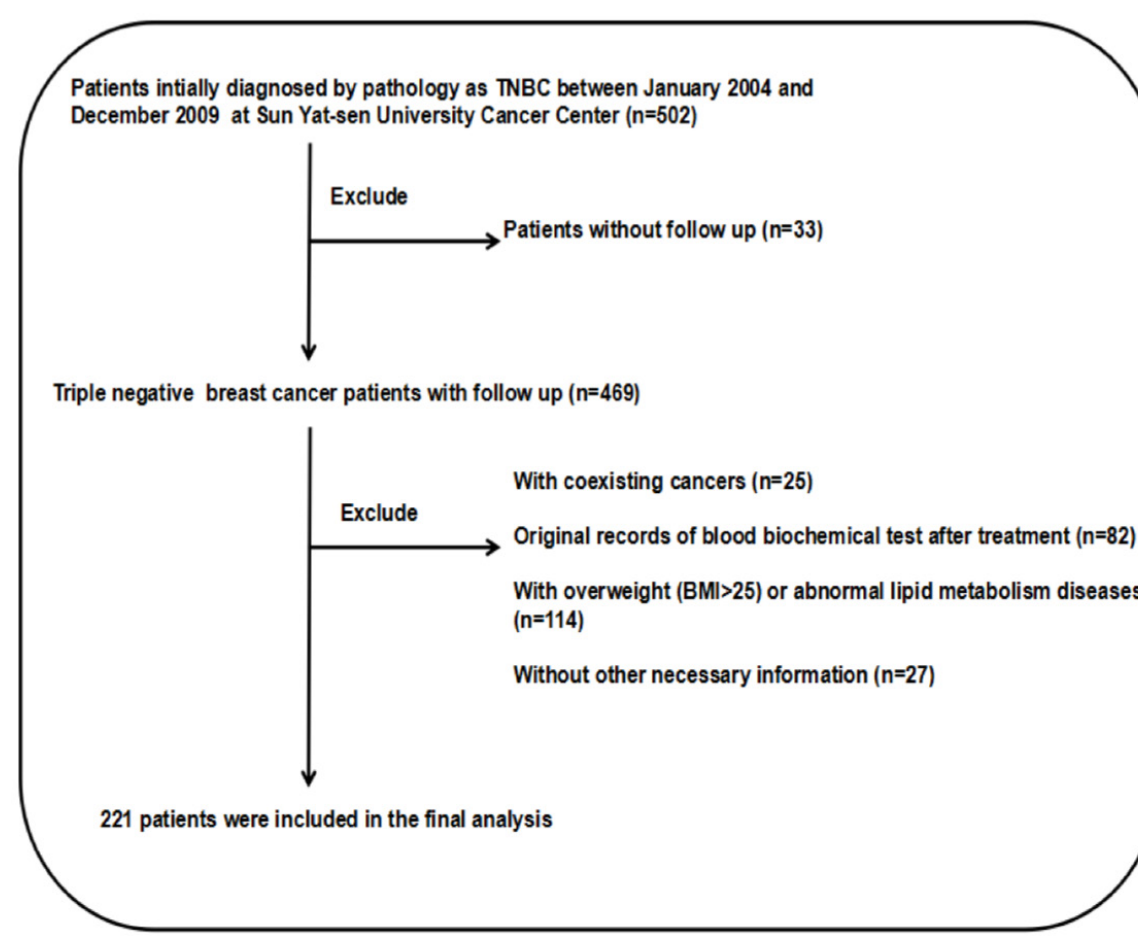

Figure 1. Flow chart of patient selection. had no original blood biochemical test records before treatment. There were also 114 patients who were obese or overweight (BMI>25) or suffered from abnormal lipid metabolism diseases. There were also 27 patients excluded due to a lack of necessary information, and 33 patients had no follow-up data. Consequently, there remained 221 patients in the cohort study. The pathological classification of 188 cases $(85.07 \%)$ was invasive ductal carcinoma. The detailed patient information is presented in Table 1.

\section{The cutoff value of the pretreatment TG level and THR and the distribution of height, weight, and BMI}

The optimal cutoff values of the pretreatment TG level and THR were determined using receiver operating curve (ROC) analyses (Fig. 2). The optimal TG level and THR cutoffs according to the highest Youden's index were $0.935 \mathrm{mmol} / \mathrm{L}$ (AUC: 0.595, 95\%CI: 0.519-0.670, $p=0.016$ ) and 0.600 (AUC: 0.622, $95 \%$ CI: 0.548-0.696, $p=0.002)$, respectively. The value was considered high or low relative to the cut-off values. The height distribution showed both the low-level group and the high-level group had similar TG levels $(1.57 \pm 0.06 \mathrm{~m}$ and $1.63 \pm 0.74 \mathrm{~m}$, respectively) and THRs $(1.58 \pm 0.06 \mathrm{~m}$ and $1.62 \pm 0.72 \mathrm{~m}$, respectively). The distribution was not significant $(p=0.498$ and $p=$ 0.563 , respectively). Similarly, the distribution of weight and BMI were not significantly different in the low and high TG and THR groups $(p>0.05)$. The distribution characteristics for the TG level and the THR with respect to height, weight, and BMI are shown in Table 2.

Table 1. Pathological Classification.

\begin{tabular}{|c|c|c|}
\hline Category & Number I & $\begin{array}{l}\text { Percent } \\
(\%)\end{array}$ \\
\hline $\begin{array}{l}\text { Invasive ductal } \\
\text { carcinoma }\end{array}$ & 188 & 85.07 \\
\hline $\begin{array}{l}\text { Invasive lobular } \\
\text { carcinoma }\end{array}$ & 2 & 0.90 \\
\hline DCISa & 1 & 0.45 \\
\hline LCICa & 19 & 8.60 \\
\hline Microinvasive carcinoma & 3 & 1.36 \\
\hline Medullary carcinoma & 6 & 2.72 \\
\hline Mucinous carcinoma & 2 & 0.90 \\
\hline Total & 221 & 100.00 \\
\hline \multicolumn{3}{|c|}{$\begin{array}{l}\text { a DCIS: ductal carcinoma in situ; LCIC: lobular } \\
\text { carcinoma in situ. }\end{array}$} \\
\hline
\end{tabular}

Figure 1. Flow chart of patient selection. 
Table 2. The distribution characteristics of $T G$ and THR, respectively, in Height, Weight and BMI.

\begin{tabular}{|c|c|c|c|c|c|c|c|}
\hline \multirow[t]{2}{*}{ Variables } & \multirow{2}{*}{$\begin{array}{l}\text { Cases } \\
(n=221)\end{array}$} & \multicolumn{2}{|l|}{ Height (m) } & \multicolumn{2}{|c|}{ Weight $(\mathrm{kg})$} & \multicolumn{2}{|l|}{ BMIa } \\
\hline & & Mean $\pm S D^{c}$ & $P^{b}$ & Mean $\pm S D^{c}$ & $P^{b}$ & Mean $\pm S D^{c}$ & $P^{b}$ \\
\hline TGc & & & 0.498 & & 0.196 & & 0.156 \\
\hline $\begin{array}{l}\text { Low } \\
\text { level }\end{array}$ & 89 & $1.57 \pm 0.06$ & & $52.16 \pm 6.29$ & & $21.02 \pm 2.13$ & \\
\hline $\begin{array}{l}\text { High } \\
\text { level }\end{array}$ & 132 & $1.63 \pm 0.74$ & & $53.39 \pm 7.35$ & & $21.51 \pm 2.73$ & \\
\hline THRc & & & 0.563 & & 0.685 & & 0.433 \\
\hline $\begin{array}{l}\text { Low } \\
\text { level }\end{array}$ & 82 & $1.58 \pm 0.06$ & & $52.65 \pm 6.65$ & & $21.14 \pm 2.34$ & \\
\hline $\begin{array}{l}\text { High } \\
\text { level }\end{array}$ & 139 & $1.62 \pm 0.72$ & & $53.04 \pm 7.15$ & & $21.42 \pm 2.66$ & \\
\hline
\end{tabular}

a BMI was defined as weight $(\mathrm{kg}) /[$ height $(\mathrm{m})] 2$; BMI: body mass index

$\mathrm{b}$ Using $\mathrm{t}$ test or ANOVA, $\mathrm{P}<0.05$ was considered statistically significant

c SD: standard deviation; TG:triacylglycerol, Low level $\leq 0.935 \mathrm{mmol} / \mathrm{L}$, High level $>0.935$ $\mathrm{mmol} / \mathrm{L}$;

THR: triacylglycerol/high density lipoprotein-cholesterol ratio, Low level $\leq 0.600$, High level $>0.600$.

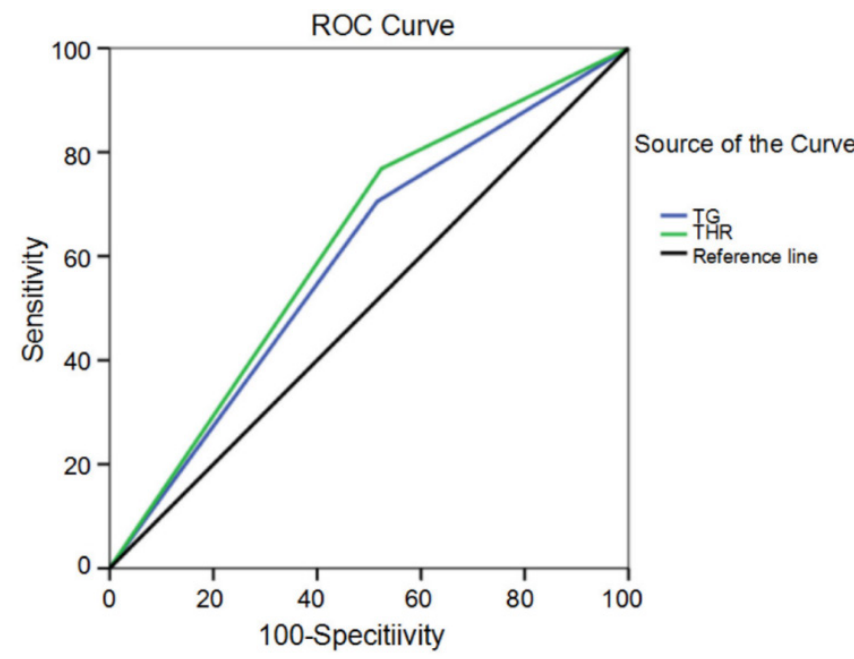

Figure 2. Receiver operating curve for TG levels and THR cutoff values plotted according to survival status.

\section{Patient clinicopathological characteristics}

There were 221 women in the study, and all of them underwent surgery. The median follow-up time was 85 months (range, 2-142 months). There were recurrences in 99 patients $(44.8 \%)$, and $95(43.0 \%)$ of the 221 breast cancer patients died. The mean age was 45.7 (range, 25-79) years. The majority of the patients were younger than 50 years of age $(68.8 \%)$. The correlations between the pretreatment TG level and THR, as well as the clinicopathological variables of TNBC patients are shown in Table 3. The mean level and standard deviation of the pretreatment TG level was $1.21 \pm 0.69 \mathrm{mmol} / \mathrm{L}$. The data indicate TG is correlated with age and menopause status $(p=0.021$ and $p=0.015$, respectively). In addition, the older and menopausal women had higher TG levels than the comparison group $(p=0.005$ and $p=0.004$, respectively). The mean and standard deviation of the THR were $0.95 \pm 0.71$. The results show that the THR was also associated with age and menopause status ( $p$ $=0.047$ and $p=0.039$, respectively). The older and menopausal patients showed higher THRs $(p=0.025$ and $p=0.010$, respectively). However, other variables such as tumor size, tumor status, TNM staging, lymph nodes metastasis, and histological grade were not significantly correlated with the pretreatment TG levels and THRs (all $p>0.05$ ).

\section{Survival and prognostic value of TG and THR}

The 10-year OS and DFS rates were 56.7\% and $54.3 \%$ for all 221 TNBC patients, respectively. The mean survival times were 101.8 (95\%CI: 95.421-108.212) months and 92.6 (95\% CI: 85.158-100.068) months, respectively (Fig. 3a, b). Furthermore, the Kaplan-Meier curve indicated that high-level TG and THR groups had worse OS and DFS rates than the low-level groups (Fig. 3 and Table 4). The univariate analysis revealed that the pretreatment TG (HR: 1.710; 95\% CI: 1.099-2.661; $p=$ 0.017) level and the THR (HR: 2.212; 95\% CI: $1.373-3.565 ; p=0.001$ ) were related with OS. The data also show tumor size, nodal status, and histological grade were correlated with the pretreatment TG level and the THR in TNBC patients (Table 5). The univariate analyses revealed that a shorter DFS was associated with a high TG (HR: 1.811; 95\%CI: 1.174-2.793; $p=0.007$ ), THR (HR: 2.252; 95\%CI: 1.412-3.592; $p=0.001$ ), tumor size, nodal status, and histological grade (Table 5). However, the multivariate survival analysis model revealed the predominantly traditional predictors of OS and DFS were nodal status (OS, HR: 2.010; 95\% CI: 1.305-3.097; $p=0.002$; DFS, HR: 1.793; 95\% CI: 1.183-2.716; $p=$ $0.006)$, and histological grade (OS, HR: 1.722; 95\% CI: 1.130-2.624; $p=0.011$; DFS, HR: $1.740 ; 95 \%$ CI: $1.156-2.621 ; p=0.008)$. The THR was an independent prognostic factor for only OS (HR: 1.935; 95\% CI: 1.032-3.629; $p=0.040$ ) (Table 6).

\section{Discussion}

Breast cancer is a complicated substantive tumor with various molecular somatotypes and clinical behaviors. Approximately 1 million people are diagnosed with breast cancer annually, and over 170,000 patients have triple negative disease [20]. Systemic chemotherapy is the only choice for patients with TNBC, and the survival rate is still poor compared with other subtypes of breast cancer. Therefore, specific biomarkers are required to guide treatment and to evaluate patient prognosis. The association of plasma lipids and cancer has recently been intensively studied. 
Table 3. Correlation between pretreatment triacylglycerol and THR level and clinicopathological variables of triple negative breast cancer patients.

\begin{tabular}{|c|c|c|c|c|c|c|c|c|c|c|c|}
\hline \multirow[t]{2}{*}{ Variables } & \multirow{2}{*}{$\begin{array}{l}\text { Cases } \\
(n=221)\end{array}$} & \multicolumn{2}{|c|}{$\mathrm{TG}^{\mathrm{d}}(\mathrm{mmol} / \mathrm{L})$} & \multicolumn{2}{|c|}{ Patients, n (\%) } & \multirow[b]{2}{*}{$\mathrm{Pb}$} & \multicolumn{2}{|l|}{ THRd } & \multicolumn{3}{|c|}{ Patients, n (\%) } \\
\hline & & Mean $\pm S^{d}$ & $\mathrm{~Pa}$ & Low TGc & High TGc & & Mean $\pm S D d$ & $\mathrm{~Pa}$ & Low THRc & High THRc & $\mathrm{Pb}$ \\
\hline Age (years) & & & $0.005^{*}$ & & & $0.021^{*}$ & & $0.025^{*}$ & & & $0.047^{*}$ \\
\hline$<=50$ & 152 & $1.12 \pm 0.63$ & & $69(45.4 \%)$ & $83(54.6 \%)$ & & $0.88 \pm 0.67$ & & $63(41.4 \%)$ & $89(58.6 \%)$ & \\
\hline$>50$ & 69 & $1.40 \pm 0.76$ & & $20(29.0 \%)$ & $49(71.0 \%)$ & & $1.11 \pm 0.78$ & & $19(27.5 \%)$ & $50(72.5 \%)$ & \\
\hline Gender & & & & & & & & & & & \\
\hline Female & 221 & $1.21 \pm 0.69$ & & $89(40.3 \%)$ & $132(59.7 \%)$ & & $0.95 \pm 0.71$ & & $82(37.1 \%)$ & $139(62.9 \%)$ & \\
\hline menopause & & & $0.004^{*}$ & & & $0.015^{*}$ & & $0.010^{*}$ & & & $0.039^{*}$ \\
\hline no & 129 & $1.10 \pm 0.61$ & & $61(47.3 \%)$ & $68(52.7 \%)$ & & $0.85 \pm 0.60$ & & $56(43.4 \%)$ & $73(56.6 \%)$ & \\
\hline yes & 82 & $1.39 \pm 0.78$ & & $25(30.5 \%)$ & $57(69.5 \%)$ & & $1.11 \pm 0.83$ & & $24(29.3 \%)$ & $58(70.7 \%)$ & \\
\hline Tumor Size $(\mathrm{cm})$ & & & 0.867 & & & 0.557 & & 0.924 & & & 0.116 \\
\hline$<=2$ & 72 & $1.23 \pm 0.79$ & & $31(43.1 \%)$ & $41(56.9 \%)$ & & $0.96 \pm 0.87$ & & $32(44.4 \%)$ & $40(55.6 \%)$ & \\
\hline$>2$ & 149 & $1.21 \pm 0.64$ & & $58(38.9 \%)$ & $91(61.1 \%)$ & & $0.95 \pm 0.62$ & & $50(33.6 \%)$ & $99(66.4 \%)$ & \\
\hline Tumor status $(\mathrm{T})$ & & & 0.134 & & & 0.224 & & 0.085 & & & 0.075 \\
\hline $\mathrm{T} 1$ & 67 & $1.17 \pm 0.76$ & & $32(47.8 \%)$ & $35(52.2 \%)$ & & $0.90 \pm 0.81$ & & $31(46.3 \%)$ & $36(53.7 \%)$ & \\
\hline $\mathrm{T} 2$ & 123 & $1.20 \pm 0.64$ & & $46(37.4 \%)$ & $77(62.6 \%)$ & & $0.95 \pm 0.64$ & & $45(36.6 \%)$ & $78(63.4 \%)$ & \\
\hline T3 & 17 & $1.13 \pm 0.44$ & & $8(47.1 \%)$ & $9(52.9 \%)$ & & $0.84 \pm 0.45$ & & $4(23.5 \%)$ & $13(76.5 \%)$ & \\
\hline $\mathrm{T} 4$ & 14 & $1.62 \pm 0.87$ & & $3(21.4 \%)$ & $11(78.6 \%)$ & & $1.41 \pm 0.86$ & & $2(14.3 \%)$ & $12(85.7 \%)$ & \\
\hline TNM Stagingd & & & 0.301 & & & 0.190 & & 0.143 & & & 0.281 \\
\hline I & 48 & $1.07 \pm 0.61$ & & $25(52.1 \%)$ & $23(47.9 \%)$ & & $0.77 \pm 0.48$ & & $23(47.9 \%)$ & $25(52.1 \%)$ & \\
\hline II & 117 & $1.25 \pm 0.70$ & & $40(34.2 \%)$ & $77(65.8 \%)$ & & $0.98 \pm 0.75$ & & $42(35.9 \%)$ & $75(64.1 \%)$ & \\
\hline III & 51 & $1.23 \pm 0.68$ & & $22(43.1 \%)$ & $29(56.9 \%)$ & & $1.02 \pm 0.74$ & & $16(31.4 \%)$ & $35(68.6 \%)$ & \\
\hline IV & 5 & $1.57 \pm 1.11$ & & $2(40.0 \%)$ & $3(60.0 \%)$ & & $1.38 \pm 1.07$ & & $1(20.0 \%)$ & $4(80.0 \%)$ & \\
\hline $\mathrm{LNM}^{\mathrm{d}}$ & & & 0.688 & & & 0.808 & & 0.362 & & & 0.470 \\
\hline Negative & 117 & $1.20 \pm 0.67$ & & $48(41.0 \%)$ & $69(59.0 \%)$ & & $0.91 \pm 0.63$ & & $46(39.3 \%)$ & $71(60.7 \%)$ & \\
\hline Positive & 104 & $1.23 \pm 0.71$ & & $41(39.4 \%)$ & $63(60.6 \%)$ & & $1.00 \pm 0.79$ & & $36(34.6 \%)$ & $68(65.4 \%)$ & \\
\hline $\begin{array}{l}\text { Histological } \\
\text { graded }^{\text {d }}\end{array}$ & & & 0.175 & & & 0.363 & & 0.055 & & & 0.852 \\
\hline G1/G2 & 115 & $1.15 \pm 0.56$ & & $43(37.4 \%)$ & $72(62.6 \%)$ & & $0.86 \pm 0.54$ & & $42(36.5 \%)$ & $73(63.5 \%)$ & \\
\hline G3 & 106 & $1.28 \pm 0.80$ & & $46(43.4 \%)$ & $60(56.6 \%)$ & & $1.05 \pm 0.85$ & & $40(37.7 \%)$ & $66(62.3 \%)$ & \\
\hline
\end{tabular}

* $\mathrm{p}<0.05$, statistically significant. a Using $\mathrm{t}$ test or ANOVA, $\mathrm{P}<0.05$ was considered statistically significant.

$\mathrm{b}$ Using Chi-squared test, $\mathrm{P}<0.05$ was considered statistically significant.

c Low TG: $\leq 0.935$ mmol/L, High TG: $>0.935$ mmol/L; Low THR: $\leq 0.600$, High THR: >0.600. d G1: well differentiated; G2: moderately differentiated; G3: poorly differentiated; TNM: tumor node metastasis; LNM: lymph nodes metatasis;

TG: triacylglycerol; THR: triacylglycerol/high density lipoprotein-cholesterol ratio; SD: standard deviation.

Table 4. Triacylglycerol level and THR value in triple negative breast cancer patients by Kaplan-Meier survival analysis (log-rank test).

\begin{tabular}{|c|c|c|c|c|c|c|c|}
\hline \multirow[t]{2}{*}{ Variable } & \multirow[t]{2}{*}{ Case } & \multicolumn{3}{|c|}{ OSa (months) } & \multicolumn{3}{|c|}{ DFSa (months) } \\
\hline & & Mean & Median & $\mathrm{P}$-value & Mean & Median & $\mathrm{P}$-value \\
\hline Total & 221 & & & & & & \\
\hline $\mathrm{TG}^{\mathrm{b}}$ & & & & $0.016^{*}$ & & & $0.006^{*}$ \\
\hline Low level & 89 & 108.666 & $\mathrm{NR}^{\mathrm{a}}$ & & 101.66 & $\mathrm{NR}^{\mathrm{a}}$ & \\
\hline High level & 132 & 95.603 & 113.233 & & 84.491 & 79.000 & \\
\hline $\mathrm{THR}^{\mathrm{b}}$ & & & & $0.001^{*}$ & & & $<0.001^{*}$ \\
\hline Low level & 82 & 115.342 & $\mathrm{NR}^{\mathrm{a}}$ & & 108.926 & NRa & \\
\hline High level & 139 & 93.771 & 106.533 & & 82.755 & 75.700 & \\
\hline
\end{tabular}

${ }^{*} \mathrm{p}<0.05$, statistically significant

a OS: overall survival; DFS: disease free survival; NR: not reached

b TG:triacylglycerol, Low level $\leq 0.935 \mathrm{mmol} / \mathrm{L}$, High level $>0.935 \mathrm{mmol} / \mathrm{L}$;

THR: triacylglycerol/high density lipoprotein-cholesterol ratio, Low level $\leq 0.600$, High level $>0.600$

Table 5. Univariate COX regression analysis for Overall Survival and Disease-free Survival in patients with triple negative breast cancer.

\begin{tabular}{|c|c|c|c|c|c|c|}
\hline \multirow[t]{2}{*}{ Variables } & \multicolumn{3}{|l|}{ OSa } & \multicolumn{3}{|l|}{ DFSa } \\
\hline & $\mathrm{HR}^{\mathrm{a}}$ & $95 \%$ CIa & $\mathrm{p}$ value & $\mathrm{HR}^{\mathrm{a}}$ & $95 \% \mathrm{CIa}^{a}$ & $\mathrm{p}$ value \\
\hline Age (years), $(\leq 50 \mathrm{vs}>50)$ & 1.309 & $0.858-1.997$ & 0.211 & 1.337 & $0.884-2.024$ & 0.169 \\
\hline Menopause(no vs yes) & 0.918 & $0.599-1.407$ & 0.694 & 0.916 & $0.603-1.391$ & 0.679 \\
\hline Tumor Size $(\mathrm{cm}),(\leq 2.5$ vs $>2.5)$ & 1.790 & $1.111-2.885$ & $0.017^{*}$ & 1.843 & $1.155-2.939$ & $0.010^{*}$ \\
\hline Nodal status (N>0/N0) & 2.277 & $1.502-3.451$ & $<0.001^{*}$ & 2.049 & $1.370-3.064$ & $<0.001^{*}$ \\
\hline Histological grade(G1-G2/G3)b & 1.918 & $1.269-2.899$ & $0.002^{*}$ & 1.884 & $1.260-2.818$ & $0.002^{*}$ \\
\hline TG(High/Low) ${ }^{c}$ & 1.710 & $1.099-2.661$ & $0.017^{*}$ & 1.811 & $1.174-2.793$ & $0.007^{*}$ \\
\hline TG(High/Low) ${ }^{c}$ & 2.212 & $1.373-3.565$ & $0.001^{*}$ & 2.252 & $1.412-3.592$ & $0.001^{*}$ \\
\hline
\end{tabular}

* $\mathrm{p}<0.05$, statistically significant a OS: overall survival; DFS: disease-free survival; HR: hazard ratio; $95 \%$ CI: 95\% confidential interval

b G1: well differentiated; G2: moderately differentiated; G3: poorly differentiated

c TG:triacylglycerol, Low $\leq 0.935 \mathrm{mmol} / \mathrm{L}$, High $>0.935 \mathrm{mmol} / \mathrm{L}$;

THR: triacylglycerol/high density lipoprotein-cholesterol ratio, Low $\leq 0.600$, High $>0.600$. 
Table 6. Multivariate COX regression analysis for Overall Survival and Disease-free Survival in patients with triple negative breast cancer.

\begin{tabular}{|c|c|c|c|c|c|c|}
\hline \multirow[t]{2}{*}{ Variables } & \multicolumn{3}{|l|}{ OSa } & \multicolumn{3}{|l|}{ DFSa } \\
\hline & $\mathrm{HR}^{\mathrm{a}}$ & $95 \% \mathrm{CI}^{\mathrm{a}}$ & $\mathrm{p}$ value & $\mathrm{HR}^{\mathrm{a}}$ & $95 \% \mathrm{CI}^{\mathrm{a}}$ & $\mathrm{p}$ value \\
\hline Tumor Size $(\leq 2.5$ vs $>2.5)$ & 1.280 & $0.777-2.109$ & 0.333 & 1.387 & $0.853-2.258$ & 0.187 \\
\hline Nodal status $(\mathrm{N}>0 / \mathrm{N}=0)$ & 2.010 & $1.305-3.097$ & $0.002^{*}$ & 1.793 & $1.183-2.716$ & $0.006^{*}$ \\
\hline Histological grade $(\mathrm{G} 1-\mathrm{G} 2 / \mathrm{G} 3)^{\mathrm{b}}$ & 1.722 & $1.130-2.624$ & $0.011^{*}$ & 1.740 & $1.156-2.621$ & $0.008^{*}$ \\
\hline TG (High/Low) ${ }^{c}$ & 1.169 & $0.650-2.100$ & 0.602 & 1.294 & $0.728-2.301$ & 0.380 \\
\hline TG $(\text { High/Low })^{c}$ & 1.935 & $1.032-3.629$ & $0.040^{*}$ & 1.806 & 0.974-3.349 & 0.061 \\
\hline
\end{tabular}

${ }^{*} \mathrm{p}<0.05$, statistically significant

a OS: overall survival; DFS: disease-free survival; HR: hazard ratio; $95 \%$ CI: 95\% confidential interval

b G1: well differentiated; G2: moderately differentiated; G3: poorly differentiated

c TG:triacylglycerol, Low $\leq 0.935 \mathrm{mmol} / \mathrm{L}$, High $>0.935 \mathrm{mmol} / \mathrm{L}$;

THR: triacylglycerol/high density lipoprotein-cholesterol ratio, Low $\leq 0.600$, High $>0.600$.

\section{a}

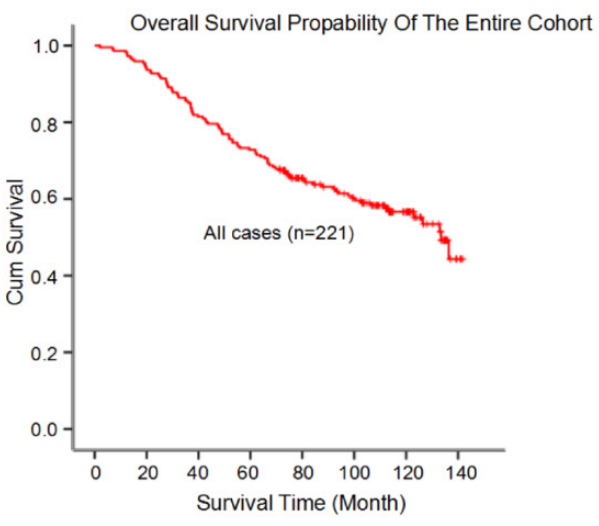

C

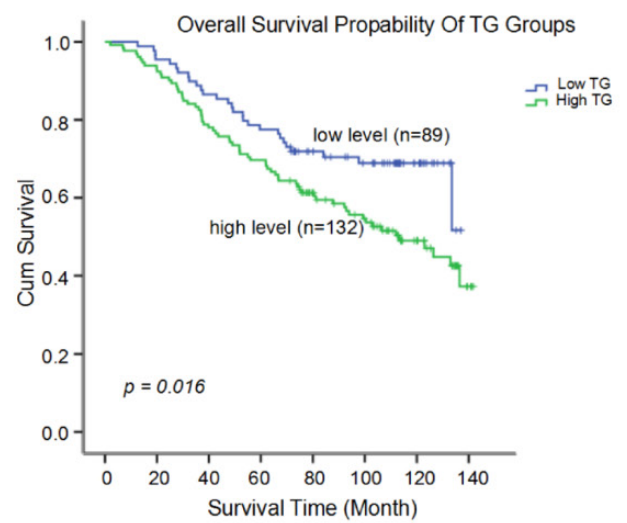

e

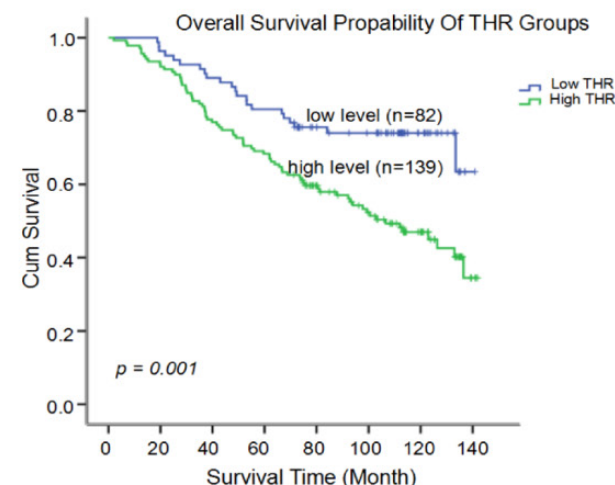

b
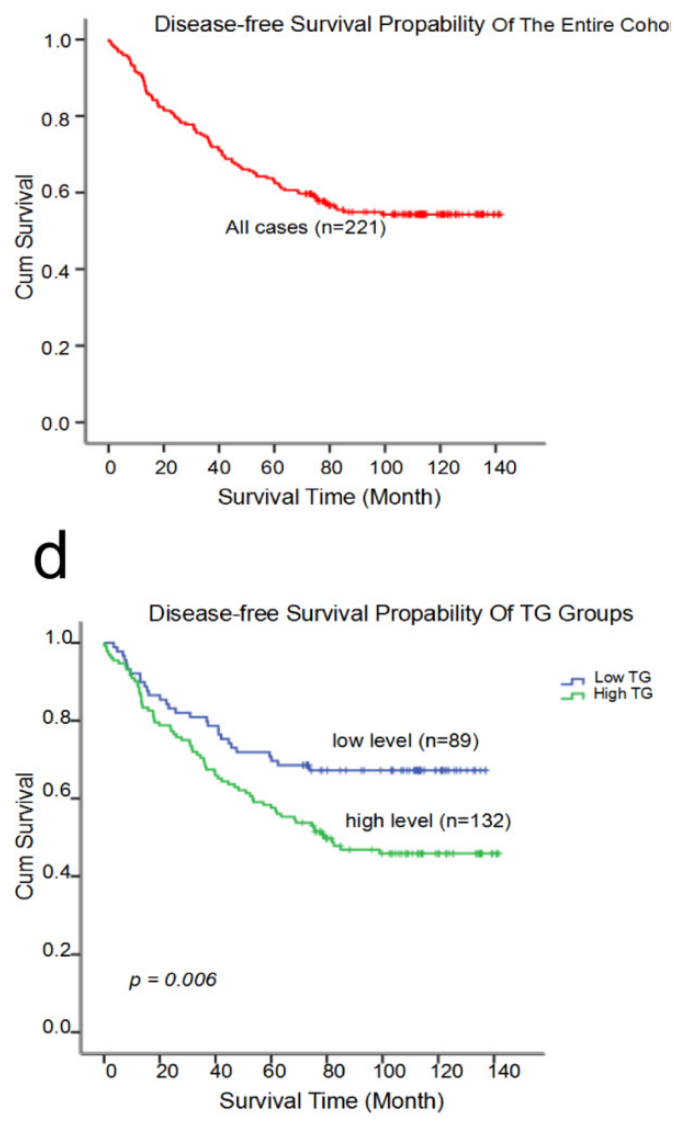

f

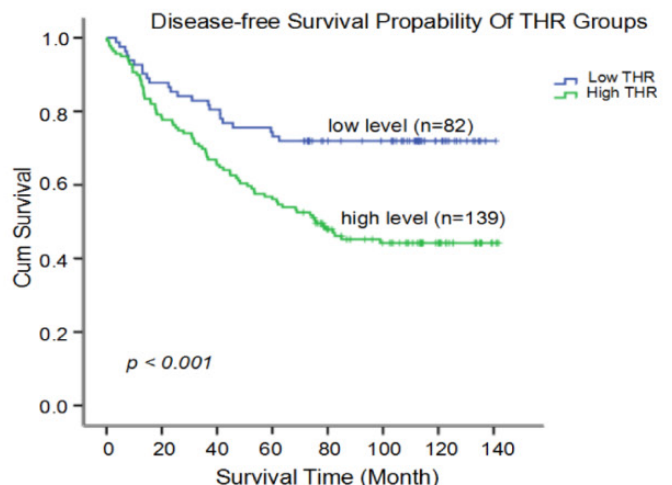

Figure 3. Kaplan-Meier estimates of the probability of survival for patients with triple negative breast cancer. (a) The overall survival (OS) rate of all 221 TNBC patients (b) The disease-free survival (DFS) rate of all 221 TNBC patients (c and d) The overall survival (OS) rates and disease-free survival (DFS) rates of the TNBC patients with different TG levels (e and $\mathbf{f}$ ) The overall survival (OS) rates and disease-free survival (DFS) rates of the TNBC patients with different THR statues. 
Metabolism and related lipid applications have been reported for several kinds of cancer, including TNBC [21,22]. In the current study, some data indicated that $59.7 \%$ and $62.9 \%$ of TNBC patients showed elevated TG levels and THRs, respectively. Patient lipid profiles are affected by obesity [23], weight, height, and BMI, which may be confounding factors and have no significant differences between groups (Table 2). The univariate analysis revealed the levels of the TG level and the THR were prognostic determinants of TNBC. Furthermore, the THR was considered to be an independent predictive factor for OS in TNBC patients in the multivariate analysis. A high THR also yielded prognostic information that was superior to the TG level for the prediction of adverse outcomes.

Lipids are composed of various types of biomolecules with many important characters in energy storage, structural composition, and signal transduction. In the clinic, blood biochemical examinations and lipid profiling are regularly tested due to their popularly established correlation with cardiovascular diseases. Triacylglycerol (TG) and cholesterol are commonly regarded as the most critical plasma lipids [24]. Previous studies have also documented the connection of serum lipids with various kinds of cancer [25-28].

Lipids are known to have an important effect in tumor development and progression [29]. Actively proliferating tumor cells need a continuous supply of lipids for membrane biogenesis [29], and non-proliferating cells require abundant lipids for enhanced signaling and apoptosis resistance [30]. Previous studies indicated that lysophosphatidic acid is an accessory for TG/free fatty acid cycling that can activate NFKB through the G-protein coupled receptor (GPCR) pathway [31]. NFKB controls the expression of the anti-apoptotic proteins Bcl-2 and Bcl-xl in many cell types [32]. Multiple previous studies [26,27,33] have shown that serum TG levels are increased in many kinds of cancers. Additionally, published data $[16,34]$ show that TG levels are strongly related with an enhanced risk of breast cancer death. This finding is consistent with our observations (Fig. 3 and Table 4). Although both the TG level and the THR were predictive factors, only the THR was considered to be an independent indicator of OS in TNBC patients (Table 6). Several studies have also indicated that low levels of HDL-C are correlated with poor prognosis in many cancers [35-38]. Although a clear mechanism is unknown, several anti-tumor mechanisms of HDL are being investigated. HDL-C is an integral component of host immunity. HDL-C induces the transcription factor activator of transcription factor 3 (ATF3), which downregulates the expression of Toll-like receptor
(TLR)-mediated tumor-promoting inflammation and promoters of tumor survival signals [39]. Conversely, HDL-C can cooperate with the adenosine triphosphate-binding cassette (ABC) transporters ABCA1 and ABCG1 to inhibit the proliferation of hematopoietic stem cells and multipotent progenitor cells [40]. Cumulatively, the abovementioned findings suggest that lipid and cholesterol homeostasis may affect immune responses that impact cancer proliferation and apoptosis. Future studies are required to increase our understanding of the role of THR in TNBC.

There are limitations in this study. First, this is a retrospective study based on a single-institutional database. Thus, the study has reduced power, and the eligibility criteria were established to minimize the selective bias. Moreover, the detailed mechanisms and the biological significance of the THR in TNBC patients require further study.

In conclusion, this retrospective cohort study is the first report to evaluate the prognostic value of the pretreatment serum TG level and THR in TNBC. The findings of our study demonstrate that the THR is an independent predictive biomarker for OS in TNBC patients and has an advantage over the serum TG level. Further clinical trials including prospective and multiple center studies are needed to better evaluate TNBC patients.

\section{Abbreviation}

TG: triacylglycerol; HDL-C: high-density lipoprotein cholesterol; THR: TG/HDL-C ratio; TNBC: triple negative breast cancer; DCIS: ductal carcinoma in situ; LCIC: lobular carcinoma in situ; TNM: tumor node metastasis; BMI: body mass index; ER: estrogen receptor; PR: progesterone receptor; ROC: receiver operating curve; AUC: area under the curve; HR: hazard ratio; 95\% CI: 95\% confidential interval; OS: overall survival; DFS: disease free survival; NR: not reached.

\section{Acknowledgments}

This study was supported by the National Natural Science Foundation of China (81472575, 81472469 and 81272514, 81372133), the Science and Technology Planning Projects of Guangdong and Guangzhou (2014J4100169, 2013B060300009, 2015B020211002, 2015B090901050 and 2014A020212079), and the Province Planning Project of Guangdong Province, China (2013B021800072). Compliance with ethical standards.

\section{Competing interests}

The authors declare that they have no competing interest to disclose. 


\section{References}

1. Dai X, Li T, Bai Z, Yang Y, Liu X, Zhan J, et al. Breast cancer intrinsic subtype classification, clinical use and future trends. American journal of cancer research. 2015; 5: 2929-43.

2. Bauer KR, Brown M, Cress RD, Parise CA, Caggiano V. Descriptive analysis of estrogen receptor (ER)-negative, progesterone receptor (PR)-negative, and HER2-negative invasive breast cancer, the so-called triple-negative phenotype: a population-based study from the California cancer Registry. Cancer. 2007; 109: 1721-8.

3. Harris LN, Broadwater G, Lin NU, Miron A, Schnitt SJ, Cowan D, et al. Molecular subtypes of breast cancer in relation to paclitaxel response and outcomes in women with metastatic disease: results from CALGB 9342. Breast cancer research: BCR. 2006; 8: R66.

4. Morris GJ, Naidu S, Topham AK, Guiles F, Xu Y, McCue P, et al. Differences in breast carcinoma characteristics in newly diagnosed African-American and Caucasian patients: a single-institution compilation compared with the National Cancer Institute's Surveillance, Epidemiology, and End Results database. Cancer. 2007; 110: 876-84.

5. Dent R, Trudeau M, Pritchard KI, Hanna WM, Kahn HK, Sawka CA, et al. Triple-negative breast cancer: clinical features and patterns of recurrence. Clinical cancer research: an official journal of the American Association for Cancer Research. 2007; 13: 4429-34.

6. Haffty BG, Yang Q, Reiss M, Kearney T, Higgins SA, Weidhaas J, et al. Locoregional relapse and distant metastasis in conservatively managed triple negative early-stage breast cancer. Journal of clinical oncology: official journal of the American Society of Clinical Oncology. 2006; 24: 5652-7.

7. Tischkowitz M, Brunet JS, Begin LR, Huntsman DG, Cheang MC, Akslen LA, et al. Use of immunohistochemical markers can refine prognosis in triple negative breast cancer. BMC cancer. 2007; 7: 134.

8. Zhong Z, Shan M, Wang J, Liu T, Shi Q, Pang D. Decreased Wnt5a Expression is a Poor Prognostic Factor in Triple-Negative Breast Cancer. Medical science monitor: international medical journal of experimental and clinical research. 2016; 22: 1-7.

9. Jia W, Wu J, Jia H, Yang Y, Zhang X, Chen K, et al. The Peripheral Blood Neutrophil-To-Lymphocyte Ratio Is Superior to the Lymphocyte-To-Monocyte Ratio for Predicting the Long-Term Survival of Triple-Negative Breast Cancer Patients. PloS one. 2015; 10: e0143061.

10. Zhang Y, Dai J, McNamara KM, Bai B, Shi M, Chan MS, et al. Prognostic significance of proline, glutamic acid, leucine rich protein 1 (PELP1) in triple-negative breast cancer: a retrospective study on 129 cases. BMC cancer. 2015; 15: 699.

11. Silva FR, de Oliveira MG, Souza AS, Figueroa JN, Santos CS. Factors associated with malnutrition in hospitalized cancer patients: a croos-sectional study. Nutrition journal. 2015; 14: 123.

12. Akuyam A, Isah HS, Ogala WN. Serum lipid profile in malnourished Nigerian children in Zaria. The Nigerian postgraduate medical journal. 2008: 15: $192-6$.

13. Liao F, He W, Jiang C, Yin C, Guo G, Chen X, et al. A high LDL-C to HDL-C ratio predicts poor prognosis for initially metastatic colorectal cancer patients with elevations in LDL-C. OncoTargets and therapy. 2015; 8: 3135-42.

14. Fan Y, Ding X, Wang J, Ma F, Yuan P, Li Q, et al. Decreased serum HDL at initial diagnosis correlates with worse outcomes for triple-negative breast cancer but not non-TNBCs. The International journal of biological markers. 2015; 30: e200-7.

15. Cvetkovic Z, Cvetkovic B, Petrovic M, Ranic M, Debeljak-Martarcic J, Vucic V, et al. Lipid profile as a prognostic factor in cancer patients. Journal of BUON: official journal of the Balkan Union of Oncology. 2009; 14: 501-6.

16. Ni H, Liu H, Gao R. Serum Lipids and Breast Cancer Risk: A Meta-Analysis of Prospective Cohort Studies. PloS one. 2015; 10: e0142669.

17. Berrino F, Villarini A, Traina A, Bonanni B, Panico S, Mano MP, et al. Metabolic syndrome and breast cancer prognosis. Breast cancer research and treatment. 2014; 147: 159-65.

18. Rodrigues Dos Santos C, Fonseca I, Dias S, Mendes de Almeida JC. Plasma level of LDL-cholesterol at diagnosis is a predictor factor of breast tumor progression. BMC cancer. 2014; 14: 132.

19. His M, Zelek L, Deschasaux M, Pouchieu C, Kesse-Guyot E, Hercberg S, et al. Prospective associations between serum biomarkers of lipid metabolism and overall, breast and prostate cancer risk. European journal of epidemiology. 2014; 29: 119-32

20. Yadav BS, Chanana P, Jhamb S. Biomarkers in triple negative breast cancer: A review. World journal of clinical oncology. 2015; 6: 252-63.

21. Andey T, Sudhakar G, Marepally S, Patel A, Banerjee R, Singh M. Lipid nanocarriers of a lipid-conjugated estrogenic derivative inhibit tumor growth and enhance cisplatin activity against triple-negative breast cancer: pharmacokinetic and efficacy evaluation. Molecular pharmaceutics. 2015; 12: 1105-20.

22. Kim S, Lee Y, Koo JS. Differential expression of lipid metabolism-related proteins in different breast cancer subtypes. PloS one. 2015; 10: e0119473.

23. Bora K, Pathak MS, Borah P, Das D. Variation in Lipid Profile Across Different Patterns of Obesity - Observations from Guwahati, Assam. Journal of clinical and diagnostic research: JCDR. 2015; 9: OC17-21.

24. Hegele RA. Plasma lipoproteins: genetic influences and clinical implications. Nature reviews Genetics. 2009; 10: 109-21.
25. Alexopoulos CG, Pournaras S, Vaslamatzis M, Avgerinos A, Raptis S. Changes in serum lipids and lipoproteins in cancer patients during chemotherapy. Cancer chemotherapy and pharmacology. 1992; 30: 412-6.

26. Yang MH, Rampal S, Sung J, Choi YH, Son HJ, Lee JH, et al. The association of serum lipids with colorectal adenomas. The American journal of gastroenterology. 2013; 108: 833-41.

27. Melvin JC, Seth D, Holmberg L, Garmo H, Hammar N, Jungner I, et al. Lipid profiles and risk of breast and ovarian cancer in the Swedish AMORIS study. Cancer epidemiology, biomarkers \& prevention: a publication of the American Association for Cancer Research, cosponsored by the American Society of Preventive Oncology. 2012; 21: 1381-4.

28. Jiang JT, Xu N, Zhang XY, Wu CP. Lipids changes in liver cancer. Journal of Zhejiang University Science B. 2007; 8: 398-409.

29. Hsu PP, Sabatini DM. Cancer cell metabolism: Warburg and beyond. Cell. 2008; 134: 703-7.

30. Rysman E, Brusselmans K, Scheys K, Timmermans L, Derua R, Munck S, et al. De novo lipogenesis protects cancer cells from free radicals and chemotherapeutics by promoting membrane lipid saturation. Cancer research. 2010; 70: 8117-26.

31. Klemm S, Zimmermann S, Peschel C, Mak TW, Ruland J. Bcl10 and Malt1 control lysophosphatidic acid-induced NF-kappaB activation and cytokine production. Proceedings of the National Academy of Sciences of the United States of America. 2007; 104: 134-8.

32. Bureau F, Vanderplasschen A, Jaspar F, Minner F, Pastoret PP, Merville MP, et al. Constitutive nuclear factor-kappaB activity preserves homeostasis of quiescent mature lymphocytes and granulocytes by controlling the expression of distinct Bcl-2 family proteins. Blood. 2002; 99: 3683-91.

33. Liu YL, Qian HX, Qin L, Zhou XI, Zhang B, Chen X. [Association of serum lipid profile with distant metastasis in breast cancer patients]. Zhonghua zhong liu za zhi [Chinese journal of oncology]. 2012; 34: 129-31.

34. Wulaningsih $\mathrm{W}$, Vahdaninia $\mathrm{M}$, Rowley $\mathrm{M}$, Holmberg $\mathrm{L}$, Garmo $\mathrm{H}$, Malmstrom $\mathrm{H}$, et al. Prediagnostic serum glucose and lipids in relation to survival in breast cancer patients: a competing risk analysis. BMC cancer. 2015; 15: 913.

35. Tamura T, Inagawa S, Hisakura K, Enomoto T, Ohkohchi N. Evaluation of serum high-density lipoprotein cholesterol levels as a prognostic factor in gastric cancer patients. Journal of gastroenterology and hepatology. 2012; 27: $1635-40$

36. Liu YL, Qian HX, Qin L, Zhou XJ, Zhang B. Serum LDL-C and LDL-C/HDL-C ratio are positively correlated to lymph node stages in males with colorectal cancer. Hepato-gastroenterology. 2011; 58: 383-7.

37. Chi PD, Liu W, Chen H, Zhang JP, Lin Y, Zheng X, et al. High-density lipoprotein cholesterol is a favorable prognostic factor and negatively correlated with C-reactive protein level in non-small cell lung carcinoma. PloS one. 2014; 9: e91080.

38. Wang L, Chi PD, Chen H, Xiang J, Xia ZJ, Zhang YJ. Low level of high-density lipoprotein cholesterol correlates with poor prognosis in extranodal natural killer/T cell lymphoma. Tumour biology: the journal of the International Society for Oncodevelopmental Biology and Medicine. 2014; 35: 2141-9.

39. De Nardo D, Labzin LI, Kono H, Seki R, Schmidt SV, Beyer M, et al. High-density lipoprotein mediates anti-inflammatory reprogramming of macrophages via the transcriptional regulator ATF3. Nature immunology. 2014; 15: 152-60.

40. Yvan-Charvet L, Pagler T, Gautier EL, Avagyan S, Siry RL, Han S, et al. ATP-binding cassette transporters and HDL suppress hematopoietic stem cell proliferation. Science. 2010; 328: 1689-93. 